\title{
Diagnostic laparoscopy in a leopard cat (Prionailurus bengalensis) with intercostal abdominal hernia and hepatic lipidosis
}

\author{
Seong-Hoon Seok ${ }^{1,3 \dagger}$, Se-Jin Park ${ }^{1, \dagger}$, Seung-Yong Lee ${ }^{1}$, Hee-Chun Lee ${ }^{2}$, Seong-Chan Yeon ${ }^{1,3, *}$ \\ ${ }^{1}$ Laboratory of Veterinary Surgery and Behavior and ${ }^{2}$ Laboratory of Veterinary Medical Imaging, College of Veterinary Medicine, \\ ${ }^{3}$ Gyeongnam Wildlife Center, Gyeongsang National University, Jinju 52828, Korea
}

(Received: December 27, 2016; Revised: March 14, 2017; Accepted: March 23, 2017)

\begin{abstract}
Intercostal abdominal hernia in the 11th intercostal space was identified in a leopard cat. Although mild leukopenia was found in laboratory examinations, no remarkable abnormality was revealed in medical imaging. To investigate abdominal organs, diagnostic laparoscopy was performed after hernia repair. In laparoscopic view, closure of the herniation site and a lesion with whitish discoloration in the liver (left medial lobe) were observed. Subsequently, laparoscopic liver biopsy was performed against the affected hepatic tissue. Histologically, the sample was diagnosed as mild hepatic lipidosis. Laparoscopy is considered useful for abdominal visceral examination and liver biopsy in a leopard cat patient.
\end{abstract}

Keywords: diagnostic laparoscopy, hepatic lipidosis, intercostal abdominal hernia, laparoscopic liver biopsy, leopard cat

It is not uncommon nowadays performing the laparoscopic procedure with a clinical purpose in wildlife. Laparoscopic surgery may offer improved visualization, smaller incision length, and decreased complications $[1,8,15]$ in wild animals as well as domestic dogs and cats. Previous studies have indicated that laparoscopic technique was a feasible method in various species, including lions [1], tigers [15], orangutan [8], and deer [12].

The leopard cat (Prionailurus bengalensis) is a member of the Felidae family which has been designated as endangered species grade II in the Republic of Korea [13]. In general, leopard cats have been commonly rescued by traumatic injuries such as traffic accidents, starvation and dehydration. A previous study reported that various hepatic lesions including hepatocellular vacuolar change, extramedullary hematopoiesis, lipogranulomas, and hepatic stellate cell hyperplasia were presented in nondomestic felids [4]. Although Goodrowe et al. [6] presented the use of laparoscopy in leopard cat for ovarian examination by referring to the domestic cat [7], to authors' knowledge, there is no report about laparoscopic operation with diagnostic intent in the leopard cat. This paper describes about surgical management of intercostal abdominal hernia and diagnostic laparoscopy in a leopard cat patient.

A 1-year-old suspected, $2 \mathrm{~kg}$, intact male leopard cat was rescued and referred to the Gyeongnam Wildlife Center. The leopard cat was suffering from exhaustion as results of dehydration and starvation, and was incidentally diagnosed with 1 $\mathrm{cm}$ diameter of intercostal abdominal hernia in the 11th intercostal space on the physical examination (Fig. 1) under sedation using $40 \mu \mathrm{g} / \mathrm{kg}$ of intramuscular medetomidine (Domitor; Pfizer, USA). After the starvation and dehydration were corrected to some extent through food supply (dry cat food, fresh meat), surgical repair of hernia was decided. The previous study revealed that various hepatic lesions were presented in nondomestic cats [4]. In addition, there may be small lesions that are not detected by computed tomography (CT), X-ray and ultrasonography examinations. To investigate overall abdominal organs as well as the liver for diagnostic purpose, laparoscopic exploration was scheduled after hernia repair.

The patient fasting was performed within $12 \mathrm{~h}$ before surgery. After tranquilization using medetomidine $(40 \mu \mathrm{g} / \mathrm{kg}$, intramuscular [IM]), an intravenous catheter was placed in the cephalic vein and venous blood samples were collected via jugular vein for a complete blood count and serum chemistry analysis. Although mild leukopenia $\left(2.88 \times 10^{9} / \mathrm{L}\right.$; normal range of 3.3 to $18.5 \times 10^{9} / \mathrm{L}$ ) was found in blood work [16], no remarkable abnormality was revealed in the abdominal radiographic, ultrasonographic and computed tomographic imaging. General anesthesia was induced with $3 \mathrm{mg} /$ $\mathrm{kg}$ propofol (Provive 1\%; Myoungmoon pharm, Korea) intra-

*Corresponding author

Tel: +82-55-772-2369, Fax: +82-55-752-7633

E-mail: scyeon@gnu.ac.kr

The first two authors contribute equally to this work. 


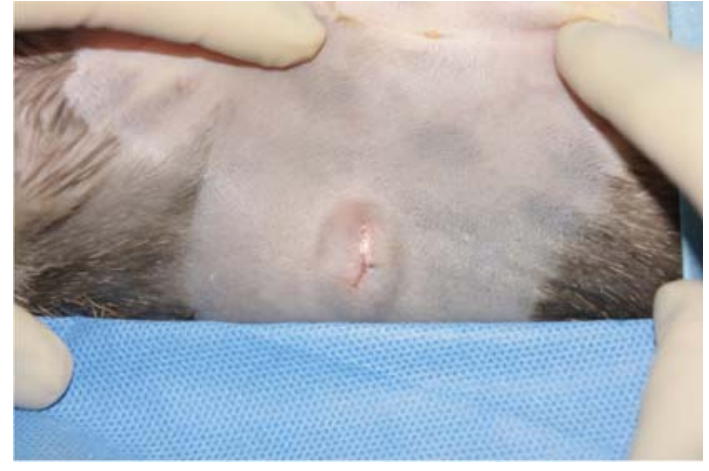

Fig. 1. Intercostal abdominal hernia of $1 \mathrm{~cm}$ diameter in the right 11th intercostal space was found on the physical examination.

venously and maintained with isoflurane (Ifran; Hana Pharm, Korea) in $100 \%$ oxygen via endotracheal intubation in a circle rebreathing system. Not only prophylactic antibiotics of cefazolin sodium $(25 \mathrm{mg} / \mathrm{kg}$, intravenous [IV], Cefazolin; Chong Kun Dang Pharmaceutical, Korea), but also analgesics of butorphanol $(0.2 \mathrm{mg} / \mathrm{kg}, \mathrm{IV}$, Butophan; Myungmoon pharm, Korea) and meloxicam $(0.2 \mathrm{mg} / \mathrm{kg}$, subcutaneous, Metacam; Boehringer Ingelheim, Germany) were administered individually before general anesthesia. Body temperature was maintained at 38 to $39^{\circ} \mathrm{C}$ using a circulating water blanket (Medi-Therm; Gaymer Industries, USA) and lactated Ringer's solution was administered via cephalic vein during the surgery at a rate of $10 \mathrm{~mL} / \mathrm{kg} / \mathrm{h}$. Electrocardiogram, capnography, pulse oximetry, rectal temperature, invasive arterial blood pressure, and respiratory rate (Datex AS/3; Datex-Ohmeda, Finland) were monitored continuously throughout the procedure.

The patient was positioned in dorsal recumbency on a surgical table aseptically after clipping of the hair. The operative field of hernia was then prepared for repair. The hernia was repaired routinely according to the small animal surgery. Following the skin incision, herniated tissue was revealed and considered as fat. When retracting the fat for removal, adhesion of the fat to the abdominal wall was identified. It was necessary to excise all affected fat for closure of the abdomen. Closure of the surgical site was performed with 3-0 polyglyconate suture material in the abdominal wall and subcutaneous tissue, and with tissue glue (Vet bond; 3M, USA) in the skin. Then the surgery was moved on to the diagnostic laparoscopy, which was performed via the two-portal system with $12 \mathrm{mmHg}$ of $\mathrm{CO}_{2}$ pneumoperitoneum. A veress needle was introduced on the $3 \mathrm{~cm}$ cranial to the umbilicus after stab incision and after that gas installation of $\mathrm{CO}_{2}$ was started using automatic insufflator (2232; Richard Wolf, Germany). After the induction of pneumoperitoneum, $5 \mathrm{~mm}$ trocar-cannula assembly was inserted $2 \mathrm{~cm}$ cranial to the umbilicus. A $5 \mathrm{~mm}, 30^{\circ}$ forward-oblique laparoscope (Panoview Plus; Richard Wolf) was entered to the abdominal cavity through this port. Under the support of laparoscopic visualization, $5 \mathrm{~mm}$ instrument port was installed $1 \mathrm{~cm}$ caudal to the last

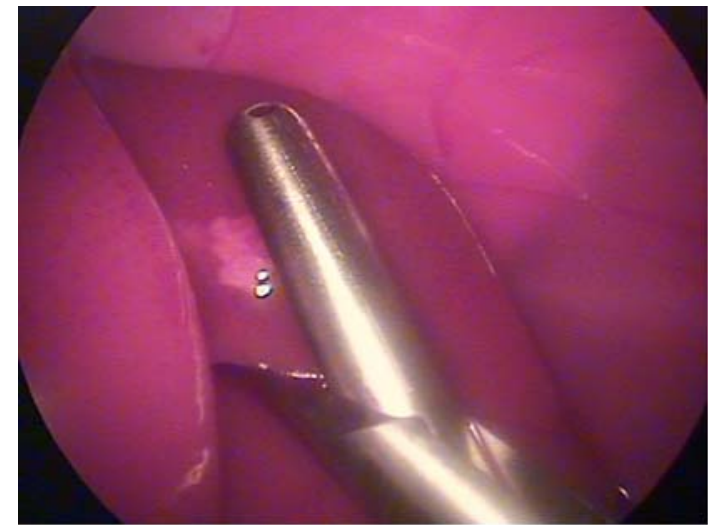

Fig. 2. Liver biopsy was performed in the color-changed lesion of left medial lobe using diagnostic laparoscopy.

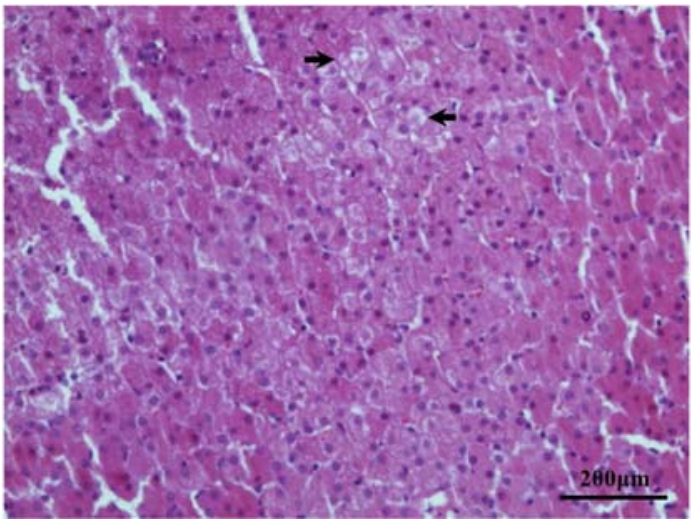

Fig. 3. Mild hepatic lipidosis was diagnosed histopathologically. Mild vacuolar change and feathery pattern of cytoplasm (arrows) were found in collected liver sample. $100 \times$. Scale Bar $=200 \mu \mathrm{m}$.

left rib, $2 \mathrm{~cm}$ lateral to the linea alba as a same manner. Laparoscopic exploration was performed including evaluation of herniated abdominal wall. In laparoscopic view, the closure of herniated site and whitish discoloration lesion in the liver (left medial lobe) were observed (Fig. 2). Then, laparoscopic biopsy was decided against the affected liver tissue with 5 $\mathrm{mm}$ laparoscopic cup biopsy forceps (Richard Wolf). Lastly, portal sites were closed routinely using 2-0 polyglyconate suture material and tissue glue. There was no cardiopulmonary dysfunction through the whole anesthetic period that including during the carbon dioxide pneumoperitoneum. The total surgical time was $72 \mathrm{~min}$. The patient showed no abnormal sign until recovered. Oral administration of cefadroxil (25 mg/kg, per orally [PO], twice a day; Mirae Pharm, Korea) and meloxicam $(0.1 \mathrm{mg} / \mathrm{kg}$, PO, once a day) was given to the patient as postoperative medication for 7 days. Histologically, the sample tissue was diagnosed as mild hepatic lipidosis (Fig. 3).

Diagnostic laparoscopy and liver biopsy were performed in the present case. Induction of $12 \mathrm{mmHg}$ of pneumoperitoneum with carbon dioxide and patient monitoring were 
applied according to the laparoscopic procedure like the domestic cat [3]. The equipment and using technique of surgery didn't show any decided difference between two species. Consequently, we encountered no clinically significant findings through the whole process. Laparoscopy has been indicated for a diagnostic purpose as well as surgical treatment in small animal practice [10]. Meanwhile, in the other wildlife, including leopard cat, laparoscopy was used for artificial insemination for reproduction of rare species $[6,9]$. However, laparoscopy is considered to the clinically feasible surgical procedure for the leopard cat patient same as the domestic cat.

It was possible to diagnose mild hepatic lipidosis via laparoscopic liver biopsy with biopsy cup instrument in the leopard cat as shown in the previous small animal study [11]. Although pathophysiology of feline hepatic lipidosis is not still fully understood [5], not only anorexia and malassimilation, but also stress due to underlying disease or inadequate food intake of healthy cat may cause syndrome development [2]. In this case, leopard cat patient with exhaustion had mild hepatic vacuolar change, but revealed no clinical sign associated with hepatic lesion until complete recovery. A recent autopsy study about hepatic lesions of nondomestic felids reported that vacuolar change in the liver was common lesion; however, primary hepatic disease was not mainly responsible for death [4].

A previous study reported that bite wounds were investigated to the most common cause of traumatic body wall hernia, including four cases of the intercostal lesions [14]. However, the research about acquired body wall herniation does not focus on wildlife yet. In the present case, it was suspected that biting caused intercostal herniation. Fortunately, no clinical sign related to herniation was identified before treatment because the perforated abdominal wall was sealed with adipose tissue.

This is the first trial of diagnostic laparoscopy and laparoscopic liver biopsy in the leopard cat patient. Diagnostic laparoscopy will offer a useful option in diagnostic method for the leopard cat as well as small animal.

\section{References}

1. Aguilar RF, Mikota SK, Smith J, Munson L, Freeman LJ, Kolata R. Endoscopic ovariohysterectomy in two lions (Panthera leo). J Zoo Wildl Med 1997, 28, 290-297.

2. Armstrong PJ, Blanchard G. Hepatic lipidosis in cats. Vet
Clin North Am Small Anim Pract 2009, 39, 599-616.

3. Beazley SG, Cosford K, Duke-Novakovski T. Cardiopulmonary effects of using carbon dioxide for laparoscopic surgery in cats. Can Vet J 2011, 52, 973-978.

4. Bernard JM, Newkirk KM, McRee AE, Whittemore JC, Ramsay EC. Hepatic lesions in 90 captive nondomestic felids presented for autopsy. Vet Pathol 2015, 52, 369-376.

5. Brown B, Mauldin GE, Armstrong J, Moroff SD, Mauldin GN. Metabolic and hormonal alterations in cats with hepatic lipidosis. J Vet Intern Med 2000, 14, 20-26.

6. Goodrowe KL, Miller AM, Wildt DE. In vitro fertilization of gonadotropin-stimulated leopard cat (Felis bengalensis) follicular oocytes. J Exp Zool 1989, 252, 89-95.

7. Goodrowe KL, Wall RJ, O'Brien SJ, Schmidt PM, Wildt DE. Developmental competence of domestic cat follicular oocytes after fertilization in vitro. Biol Reprod 1988, 39, 355-372.

8. Hendrix PK. Anesthetic management of an orangutan (Pongo abelii/pygmaeus) undergoing laparoscopic tubal ligation. J Zoo Wildl Med 2006, 37, 531-534.

9. Howard JG, Roth TL, Byers AP, Swanson WF, Wildt DE. Sensitivity to exogenous gonadotropins for ovulation induction and laparoscopic artificial insemination in the cheetah and clouded leopard. Biol Reprod 1997, 56, 1059-1068.

10. Matyjasik H, Adamiak Z, Pesta W, Zhalniarovich Y. Laparoscopic procedures in dogs and cats. Pol J Vet Sci 2011, 14, 305-316.

11. Petre SL, McClaran JK, Bergman PJ, Monette S. Safety and efficacy of laparoscopic hepatic biopsy in dogs: 80 cases (2004-2009). J Am Vet Med Assoc 2012, 240, 181-185.

12. Posner LP, Woodie JB, Curtis PD, Erb HN, Gilbert R, Adams WA, Gleed RD. Acid-base, blood gas, and physiologic parameters during laparoscopy in the head-down position in white-tailed deer (Odocoileus virginianus). J Zoo Wildl Med 2005, 36, 642-647.

13. Rho P. Use of GIS to develop a multivariate habitat model for the leopard cat (Prionailurus bengalensis) in mountainous region of Korea. J Ecol Field Biol 2009, 32, 229-236.

14. Shaw SR, Rozanski EA, Rush JE. Traumatic body wall herniation in 36 dogs and cats. J Am Anim Hosp Assoc 2003, 39, 35-46.

15. Steeil JC, Sura PA, Ramsay EC, Reilly S, Seddighi R, Whittemore J. Laparoscopic-assisted ovariectomy of tigers (Panthera tigris) with the use of the LigaSure device. J Zoo Wildl Med 2012, 43, 566-572.

16. Teare JA; International Species Information System. ISIS reference ranges for physiological values in captive wildlife. 2002 ed. International Species Information System, Apple Valley, 2002. 